\title{
Fractal Nonstandard American Option Pricing Model
}

\author{
YAN Yong-xin \\ Tianjin Normal University, Tianjin, China
}

\begin{abstract}
The empirical study shows that the return rate of the stock price has a long memory, which can be described by fractal Brown motion. The fact that fractal Brown motion does not have the characteristics of Markov makes the American option value depends on the price change path of the underlying asset. And the ordinary American option pricing model underestimates the American option value. In order to fully reflect the long memory of the underlying asset return rates, we propose fractal American option pricing model, fractal Bermuda option pricing model, and a fractal combination of American option pricing model. Fractal American option value is greater than the ordinary American option value.
\end{abstract}

Keywords: fractal American option, fractal Bermudan option, fractal combination American option

\section{Introduction}

In June 1992, Shanghai Stock Exchange began trading warrants, which had greatly damaged the interests of ordinary investors due to excessive speculation, and it stopped trading in June 1996. In August 22, 2005, Baoshan Iron and Steel Company Limited (BSIS) issued derivative call warrants, and Wuhan Iron and Steel Company Limited (WHIS) issued derivative put warrants in November 23, 2005.

The Central Huijin Investment Ltd. signed a foreign exchange options trading agreement with Bank of China Limited on January 5, 2005, China Construction Bank Corporation on January 12, 2005, and Industrial and Commercial Bank of China Limited on April 30, 2005, respectively. On April 1, 2011, State Administration of Foreign Exchange allowed qualified commercial banks to engage in foreign exchange options.

In order to stimulate staff's work enthusiasm, some companies issue call options to employees or management. If option expiration time is five years, employees can exercise the option at any time in the fifth year, which is equivalent to the delayed execution of American option, or the advance execution of a European option. The standard European option is priced with Black-Scholes-Merton (BSM) (1973) model, Decreusefond and Ustunel (1999) developed the European option pricing model with the path dependence of integral (Stratonovich integral), which is based on fractal Brown motion.

In fact, the European option can be executed both at maturity and in advance. American option can be exercised at any time during the maturity of validity, or can be terminated in advance. We can also open an execution window during the effective maturity of European option, and we called Bermudan option.

For the standard American option, if we use binomial tree pricing model (Cox, Ross, \& Rubinstein, 1979), computers must be used. If we use continuous time American option pricing model and continuous time foreign

YAN Yong-xin, Ph.D., Professor, School of Management, Tianjin Normal University.

Correspondence concerning this article should be addressed to YAN Yong-xin, Room 2-2501, Zilai Garden, Shuangfeng Road, Nankai District, Tianjin, 300073, China. E-mail: yanyongxin59@126.com. 
exchange option pricing model, which are put forward by Yan and Zhao (2008) and Yan (2009), we can decrease pricing cost of the standard American option. The advance execution European option pricing models and the advance termination American option-pricing model presented by Yan (2009) laid the theoretical foundation for the study of the Bermudan option pricing model.

In option pricing, we assume that the logarithmic return rate of underlying asset obey normal distribution, and the volatility is constant. CITIC Securities (CITIC Securities Company Limited) financial engineering research group (2006) select the Shanghai Composite Index and Shenzhen Component Index's daily closing price from March 21st, 2003 to March 21st, 2006 as the sample data for normality test. The empirical research shows that the two index daily return rates showed fractal Brown motion rather than Brown motion.

Fractal Brown motion does not have the characteristics of Markov processes, which makes the American option value is based on the changing path of the underlying asset prices. Fractal Brown motion can better reflect the long-term memory of the underlying asset return rates. Due to the presence of long memory, the underlying asset price fluctuations will be influenced by the initial status, and then affects the American option value. Continuous time American option pricing model (Yan \& Zhao, 2008; Yan, 2009) does not reflect the long memory of time series, and the fractal model of American option pricing fully reflects the long memory of time series. Thus, the fractal American option-pricing model is more accurate than the continuous time American option-pricing model.

The second part of this paper presents fractal American option pricing model, the third part puts forward the fractal Bermudan option-pricing model, the fourth part raises the fractal combination American option pricing model, and the fifth part is the conclusion of the thesis.

\section{Fractal American Option Pricing Model}

Using the geometric Brown motion to describe the return rate of a financial asset is not accurate enough, because the geometric Brown motion is only a special case of fractal Brown motion. Geometric Brown motion is fractal Hurst index $H=1 / 2$ Brown movement. Under the assumption that the price of underlying asset meets the fractal Brown motion:

$$
d S_{t}=\mu S_{t} d t+\sigma S_{t} d W^{H}, S_{t}>0,0 \leq t \leq T
$$

where $H$ is hurst index; $W^{H}$ is fractal Brown motion under $P$ measure.

Assuming the risk free interest rate $r$ and the underlying asset return rate volatility $\sigma$ are constants, and the asset price process without arbitrage opportunities can be described with the following formula:

$$
S_{t}=S_{0} \exp \left(\sigma \tilde{W}^{H}+r t-\frac{1}{2} \sigma^{2} t^{2 H}\right)
$$

where $\widetilde{W}^{H}$ is fractal Brown motion under $Q$ measure.

If execution price is $X$ and time to maturity is $T$, at time zero the value of fractal American call option and put option can be expressed by:

among them:

$$
\begin{gathered}
c_{A f}=S_{0} e^{(r-q) T} N\left(d_{1}\right)-X N\left(d_{2}\right) \\
p_{A f}=X N\left(-d_{2}\right)-S_{0} e^{(r-q) T} N\left(-d_{1}\right)
\end{gathered}
$$

$$
d_{1,2}=\frac{\ln \left(S_{0} / X\right)+(r-q) T \pm \frac{1}{2} \sigma^{2} T^{2 H}}{\sigma \sqrt{T^{2 H}}}
$$




$$
N(d)=\frac{1}{\sqrt{2 \pi}} \int_{-\infty}^{d} e^{-\frac{1}{2} x^{2}} d x
$$

In fractal American option pricing model, we use $T^{2 H}$ to replace $T$, which is used in American option pricing model. When option maturity $T$ is determined, option values are the same as the value under American option pricing mode. However, option values are different using the fractal American option pricing, which is related to the Hurst index $H$.

\section{Fractal Bermudan Option Pricing Model}

\section{Advance Execution Fractal European Option Pricing Model}

We assume $T$ is the time to maturity of European option, $T_{1}$ is time we commence to exercise the European options, and $0 \leq T_{1} \leq T$ in the period [0, $\left.T_{1}\right]$, European option cannot be exercised; in the period $\left[T_{1}, T\right]$, European option can be exercised. The advance execution European option gains can be invested in the risk-free assets. Advance execution fractal European option pricing model is:

$$
\begin{gathered}
c_{E f a}=\left[S e^{-q T} N\left(d_{1}\right)-X e^{-r T} N\left(d_{2}\right)\right] e^{f_{T_{1}-T}\left(T-T_{1}\right)} \\
p_{E f a}=\left[X e^{-r T} N\left(-d_{2}\right)-S e^{-q T} N\left(-d_{1}\right)\right] e^{f_{T_{1}-T}\left(T-T_{1}\right)}
\end{gathered}
$$

where $C_{E f a}$ is the value of advance execution fractal European call option; $p_{E f a}$ is the value of advance execution fractal European put option; $q$ is the annual return rate of underlying assets; $r$ is risk-free interest rate; $S$ is the current price of underlying asset; $X$ is option's execution price; $f_{T_{1}-T}$ is the forward interest rate; $\sigma$ is the return rate volatility of underlying asset.

If the advance execution time is equal to the European option deadline, $T_{1}=0$, then the value of advance execution European option equals to the value of American option.

\section{Advance Termination Fractal American Option Pricing Model}

Assuming $T$ is the maturity time of American option, which can be exercised in the period of $\left[0, T_{1}\right]$ but cannot be exercised in the period of $\left[T_{1}, T\right]$, which is equivalent to advance termination American option. In this case, the value of advance termination fractal American option is:

$$
\begin{gathered}
c_{A f a}=\left[S e^{(r-q) T} N\left(d_{1}\right)-X N\left(d_{2}\right)\right] e^{-f_{T_{1}-T}\left(T-T_{1}\right)} \\
p_{A f a}=\left[X N\left(-d_{2}\right)-S e^{(r-q) T} N\left(-d_{1}\right)\right] e^{-f_{T_{1}-T}\left(T-T_{1}\right)}
\end{gathered}
$$

where $c_{A f a}$ is the value of advance termination fractal American call option; $p_{A f a}$ is the value of advance termination fractal American put option.

If advance termination time equals to the time to maturity of American option, advance termination American option value is equal to the European option value, and forward interest rate equals to the spot rate.

\section{Fractal Bermudan Option Pricing Model}

In order to establish the fractal Bermudan option pricing model, we assume that $T$ is the time to maturity of Bermudan option. It $T_{1}$ is the beginning of execution time of Bermudan option and $T_{2}$ is the end of the execution time of Bermudan option, we can get $0<T_{1}<T_{2}<T$. Bermuda option can be exercised in the period of $\left[T_{1}, T_{2}\right]$ but cannot be exercised in the periods of $\left[0, T_{1}\right]$ and $\left[T_{2}, T\right]$. The Bermuda option is a compound option which is equivalent to the combination of the advance execution European options and advance termination American option. Fractal Bermudan option value can be expressed by: 


$$
\begin{gathered}
c_{B f}=\left[S e^{-q T} N\left(d_{1}\right)-X N\left(d_{2}\right) e^{-r T}\right] e^{f_{T_{1}-T}\left(T-T_{1}\right)-f_{T_{2}-T}\left(T-T_{2}\right)} \\
p_{B f}=\left[X N\left(-d_{2}\right) e^{-r T}-S e^{-q T} N\left(-d_{1}\right)\right] e^{f_{T_{1}-T}\left(T-T_{1}\right)-f_{T_{2}-T}\left(T-T_{2}\right)}
\end{gathered}
$$

or:

$$
\begin{aligned}
& c_{B f}=c_{E} e^{f_{T_{1}-T}\left(T-T_{1}\right)-f_{T_{1}-T}\left(T-T_{2}\right)} \\
& p_{B f}=p_{E} e^{f_{T_{1}-T}\left(T-T_{1}\right)-f_{T_{2}-T}\left(T-T_{2}\right)}
\end{aligned}
$$

where $C_{B f}$ is the fractal Bermuda call option value; $p_{B f}$ is the fractal Bermuda put option value.

If the beginning of execution period of Bermudan option is zero, $T_{1}=0$, and the end of execution period equals to option deadline $T_{2}=T$, then Bermudan option value equals to the American option value. If the beginning of execution period of Bermudan option equals to the option deadline $T_{1}=T$, the expired term also equals to the option deadline $T_{2}=T$, then Bermudan option value equals to European option value. Table 1 lists the nonstandard fractal option pricing model.

Table 1

Fractal Option Pricing Model

\begin{tabular}{lll}
\hline Option name & Call option & Put option \\
\hline Advance execution European option & $C_{E f a}=c_{E f} e^{f_{T_{1}-T}\left(T-T_{1}\right)}$ & $p_{E f a}=p_{E f} e^{f_{T_{1}-T}\left(T-T_{1}\right)}$ \\
Advance termination American option & $C_{A f a}=c_{A f} e^{-f_{T_{1}-T}\left(T-T_{1}\right)}$ & $p_{A f a}=p_{A f} e^{-f_{T_{1}-T}\left(T-T_{1}\right)}$ \\
Bermudan option & $C_{B f}=C_{E f} e^{f_{T_{1}-T}\left(T-T_{1}\right)-f_{T_{1}-T}\left(T-T_{2}\right)}$ & $p_{B f}=p_{E f} e^{f_{T_{1}-T}\left(T-T_{1}\right)-f_{T_{2}-T}\left(T-T_{2}\right)}$ \\
\hline
\end{tabular}

According to the research above, we find that:

- As the execution point of European option is the latest, the execution period is the shortest, so the option value is the lowest;

- As the American option execution point is the earliest, execution period is the longest, so the value of the option is the highest;

- If the interest rate curve is a horizontal line, and the execution period is equal, then the option value is equal, regardless the sequence of execution time. For example, if an option with a maturity period of three years, the advance termination American option is exercised in the first year, Bermudan option is exercised in the second year, advance execution European option is exercised in the third year, the value of these three options is equal;

- If American option's deferred exercise time is equal to European option's advance execution time, the value of advance execution European option is equal to the value of the deferred execution American option.

\section{Fractal Combination American Option Pricing Model}

In the validity period of the option, the American option buyer can exercise the American option for many times. If the validity period of the combination American option is one year, the option can be exercised from the beginning of each month to the end of each month in the year, which means that the option will be exercised for 12 times.

For the buyers of combination American call option, if the price of the underlying asset is lower than the execution price of an option, they can give up the option, or they can only exercise the option for one time in every month. For the buyers of combination American put option, if the price of the underlying is greater than 
the execution price, they can also give up the put option.

In order to calculate present value of combination American option, we assume that in the valid period the combination American option were executed $n$ times, the expiration time of the combination American option are $t_{1}, t_{2}, \ldots, t_{\mathrm{n}}$. The $i(i=1,2, \ldots, n)$ respectively, American option value is equal to the present value of advance execution European option.

$$
\begin{gathered}
c_{A, i}=\left[S e^{-q t_{i}} N\left(d_{1, i}\right)-X e^{-r_{i} t_{i}} N\left(d_{2, i}\right)\right] e^{f_{t_{i-1}-t_{i}}\left(t_{i}-t_{i-1}\right)} \\
p_{A, i}=\left[X e^{-r_{i} t_{i}} N\left(-d_{2, i}\right)-S e^{-q t_{i}} N\left(-d_{1, i}\right)\right] e^{f_{t_{i-1}-t_{i}}\left(t_{i}-t_{i-1}\right)}
\end{gathered}
$$

where $f_{t_{i-1}-t_{i}}$ is the forward interest rates of $t_{i}-t_{i-1}$ years, if the interest rate curve is a straight line, forward rates equal to the spot interest rate; $t_{0}=0$, equivalent to the current time.

$$
d_{1, i}=\frac{\ln (S / X)+\left(r_{i}-q\right) t_{i}+0.5 \sigma^{2} t_{i}^{2 H}}{\sigma \sqrt{t_{i}^{2 H}}}, d_{2, i}=d_{1, i}-\sigma \sqrt{t_{i}^{2 H}}
$$

Fractal combination American option value:

$$
\begin{gathered}
\left.c_{A f c}=\sum_{i=1}^{n} c_{A, i}=\sum_{i=1}^{n}\left\{S e^{-q t_{i}} N\left(d_{1, i}\right)-X e^{-r_{i} t_{i}} N\left(d_{2, i}\right)\right] e^{f_{t_{i-1}-t_{i}}\left(t_{i}-t_{i-1}\right)}\right\} \\
p_{A f c}=\sum_{i=1}^{n} p_{A, i}=\sum_{i=1}^{n}\left\{\left[X e^{-r_{i} t_{i}} N\left(-d_{2, i}\right)-S e^{-q t_{i}} N\left(-d_{1, i}\right)\right] e^{f_{t_{i-1}-t_{i}}\left(t_{i}-t_{i-1}\right)}\right\}
\end{gathered}
$$

where $C_{A f c}$ is fractal combination American call option value; $p_{A f c}$ is fractal combination American put option value.

Other parameters of the fractal American option are constant, there is a relationship between fractal option value and Hurst index $H$. The larger of the $H$ is, the bigger of the fractal American option value is; the smaller of the $H$ is, the smaller of the fractal American option value is.

\section{Empirical Study}

The annual return rate Hurst of Shanghai and Shenzhen 300 index (HS 300 index, 1990-2012) is $H=$ 0.582 , where $H>0.5$ shows that the HS 300 index has a long memory. The standard deviation of logarithmic return rate is $20 \%$ (2012), and the one-year borrowing rate between banks is $5 \%$ (November 2012). Assuming that the interest rate curve is a straight line, and the period to maturity of option is six months. The option execution price equal to 2,524.41 points, the closing price as at January 4, 2013, the dividend rate of HS 300 index is $2 \%$. We exercise American option from January to June, March to April for Bermudan option, and we exercise the combination American option in May and June for one time respectively. The fractal values of these three options are calculated separately.

Table 2

Comparison of Fractal Value of Options

\begin{tabular}{llll}
\hline Option types & $\begin{array}{l}\text { Call options } \\
\text { (CNY) }\end{array}$ & $\begin{array}{l}\text { Put options } \\
\text { (CNY) }\end{array}$ & Remarks \\
\hline Ordinary European option & 172.39 & 135.18 & \\
Fractal European option & 153.21 & 116.00 & \\
Ordinary American option & 176.75 & 138.60 & \\
Fractal American option & 157.09 & 118.94 & \\
Ordinary Bermudan option & 173.83 & 136.31 & \\
Fractal Bermudan option & 154.49 & 116.97 & $147.77+173.11,115.89+135.74$ \\
Ordinary combination American option & 320.88 & 251.63 & $138.94+173.11,107.06+116.48$ \\
\hline Fractal combination American option & 312.05 & 223.54 & \\
\hline
\end{tabular}


According to the result of Table 2, we come to the following conclusions:

- When $H>0.5$ or $T=1$, the value of fractal option is equal to the value of ordinary option. The value of ordinary American option is higher than the value of European option. The value of Bermuda option is higher than the value of ordinary European option, and lower than the value of ordinary American option;

- When $H>0.5$, the conclusions depend on the value of $T$, which is period to maturity. When $T<1$, the value of fractal option is lower than the value of ordinary option; when $T>1$, the value of fractal option is higher than the value of ordinary option;

- When $H>0.5$, the value of fractal option is lower than the value ordinary option.

\section{Conclusions}

For the nonstandard options, it is common to exercise the advance execution European option and Bermudan option, and advance termination American option to use less. The combination European options and American option are traded on the Organization for Trade Cooperation (OTC). Bermudan option is traded in the pit.

For the same underlying asset, if the interest rate curve is a straight line, the execution time interval length of options are the same, the value of advance execution fractal European option, value of advance termination fractal American option and value of fractal Bermudan option are the same, it does not matter with execution time sequence.

When $H>0.5$, if the maturity period of the option $T<1$, the value of fractal option is lower than the value of the ordinary option; if $T>1$, the value of fractal option is higher than the value of the ordinary option. When $H=0.5$, the value of fractal option is equal to the value of the ordinary option. When $H<0.5$, the value of fractal option is higher than the value of ordinary option.

\section{References}

Black, F., \& Scholes, M. (1973). The pricing of option and corporate liabilities. Journal of Political Economy, 81, 637-654.

Cox, J. C., Ross, S. A., \& Rubinstein, M. (1979). Option pricing: A simplified approach. Journal of Financial Economics, 7 , 229-263.

Decreusefond, L., \& Ustunel, A. S. (1999). Stochastic analysis of the fractional Brownian motion. Potential Analysis, 10, 177-214.

Du, G. X., \& Ning, X. X. (2007). Multifractal analysis on Shanghai stock market. System Engineering Theory and Practice, 10, 4-47.

Merton, R. C. (1973). Theory of rational option pricing. Bell Journal of Economics and Management Science, 4, 141-183.

Su, C. J., Miao, X. B., \& Liu, X. (2005). Nonlinear characteristics and fractal dimension analysis of Chinese stock markets. System Engineering Theory and Practice, 5, 68-73.

Yan, Y. X. (2009). Continuous-time American foreign exchange option pricing model. China-USA Business Review, 9, $29-33$.

Yan, Y. X., \& Hu, Y. L. (2010). Early exercise European option and early termination American option pricing models. China Business Review, 11, 21-25.

Yan, Y. X., \& Zhao, J. Z. (2008). A simple American option pricing model. China-USA Business Review, 4, 20-24.

Ye, H., \& Lin, S. S. (2005). The study on the efficiency of China's stock market son the basis of fractal theory. Social Science, 2, 222-226. 